\title{
Influenza A H3N2 subtype virus NS1 protein targets into the nucleus and binds primarily via its C-terminal NLS2/NoLS to nucleolin and fibrillarin
}

Krister Melén ${ }^{1 *}$, Janne Tynell ${ }^{1}$, Riku Fagerlund ${ }^{2}$, Pascal Roussel ${ }^{3}$, Danièle Hernandez-Verdun ${ }^{4}$ and llkka Julkunen ${ }^{1}$

\begin{abstract}
Background: Influenza A virus non-structural protein 1 (NS1) is a virulence factor, which is targeted into the cell cytoplasm, nucleus and nucleolus. NS1 is a multi-functional protein that inhibits host cell pre-mRNA processing and counteracts host cell antiviral responses. Previously, we have shown that the NS1 protein of the H3N2 subtype influenza viruses possesses a C-terminal nuclear localization signal (NLS) that also functions as a nucleolar localization signal (NoLS) and targets the protein into the nucleolus.

Results: Here, we show that the NS1 protein of the human H3N2 virus subtype interacts in vitro primarily via its C-terminal NLS2/NoLS and to a minor extent via its N-terminal NLS1 with the nucleolar proteins, nucleolin and fibrillarin. Using chimeric green fluorescence protein (GFP)-NS1 fusion constructs, we show that the nucleolar retention of the NS1 protein is determined by its C-terminal NLS2/NoLS in vivo. Confocal laser microscopy analysis shows that the NS1 protein colocalizes with nucleolin in nucleoplasm and nucleolus and with B23 and fibrillarin in the nucleolus of influenza A/Udorn/72 virus-infected A549 cells. Since some viral proteins contain NoLSs, it is likely that viruses have evolved specific nucleolar functions.
\end{abstract}

Conclusion: NS1 protein of the human H3N2 virus interacts primarily via the C-terminal NLS2/NoLS and to a minor extent via the N-terminal NLS1 with the main nucleolar proteins, nucleolin, B23 and fibrillarin.

Keywords: Influenza A virus, NS1 protein, NoLS, Nucleolus, Nucleolin, B23, Fibrillarin

\section{Background}

Influenza A virus genome consists of eight separate RNA segments, which encode for 12 viral structural and nonstructural proteins [1]. In addition to the viral hemagglutinin (HA), nonstructural protein 1 (NS1) is one of the major viral virulence factors. The evolution of NS genes appears to be species-specific, and the evolution of present seasonal human NS genes began in 1918, when H1N1 type viruses emerged and became pandemic [2]. With the most recent pandemic in 2009 caused by the swine-origin influenza A virus, the NS gene was

\footnotetext{
* Correspondence: krister.melen@thl.fi

'Virology Unit, Department of Infectious Disease Surveillance and Control, National Institute for Health and Welfare (THL), Mannerheimintie 166, FIN-00300 Helsinki, Finland

Full list of author information is available at the end of the article
}

changed, and it was originating from classical swine influenza viruses [3].

Influenza A virus NS1 is a multi-functional protein that contains an N-terminal dsRNA-binding domain and a C-terminal effector domain. Experiments with the human H3N2 influenza A/Udorn/72 virus demonstrated that the primary role of the NS1 dsRNA-binding activity is to inhibit the activation of IFN-induced 2'-5' oligo (A) synthetase/RNase L pathway [4]. Instead, experiments with the mouse-adapted H1N1 influenza A/PR8/34 virus indicated that the RNA-binding domain participates in the NS1 protein-mediated inhibition of the activation of the retinoic acid-inducible gene I (RIG-I) [5,6] which is required for the influenza A virus-induced cytokine gene expression [7-9]. The effector domain of NS1 binds to two cellular proteins that are essential for the 3'

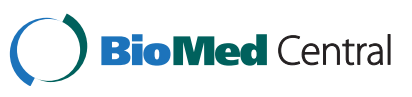


end processing of cellular pre-mRNAs [10-12]. As a result, the processing of cellular pre-mRNAs, including interferon- $\beta$ (IFN- $\beta$ ), is inhibited [12-15]. In addition, the NS1 protein of influenza A virus has been shown to interact with protein kinase $\mathrm{R}$ (PKR), PACT, Crk/CrkL, TRIM25 and the p85 component of the PI-3 kinase pathway [16-21].

Eukaryotes have a nucleolus, which is a relatively large, dynamic and highly organized non-membranous subcompartment of the nucleus. The nucleolus is the site for ribosomal RNA synthesis, processing and maturation $[22,23]$. Recently, it has become apparent that nucleolus also has a role in regulating the cell cycle, tumor suppression and oncogenic activities, the assembly of signal recognition particle (SRP), the control of aging and the modulation of telomerase functions [24-26]. Some of these functions are mediated through the sequestration of transcription factors that control the cell cycle $[26,27]$. Recent studies show that the nucleolus is made up of numerous protein-protein and protein-nucleic acid interactions that are constantly changing in response to the metabolic conditions of the cell [28]. Nucleolus is divided into three discrete regions: fibrillar centres, surrounded by dense fibrillar component (DFC), which in turn is surrounded by a granular component (GC) (reviewed in $[23,29]$ ).

Three distinct subsets of nucleolar proteins have been identified. Primarily, fibrillarin is a small nucleolar ribonucleoprotein (snoRNP), which is associated with early pre-rRNA transcripts during elongation and is localizing to DFC. B23/NPM protein is a putative ribosome assembly factor involved in $28 \mathrm{~S}$ rRNA processing and ribosome assembly that localized in the GC, while the third major nucleolar protein, nucleolin, is involved in the processing of precursor rRNAs [30].

Nucleolar localization signals (NoLSs) that regulate nucleolar localization and retention are usually rich in arginine and lysine residues, which overlap with NLSs. However, there is no obvious consensus NoLS sequence or structure [31-33]. Nuclear proteins pass through the nucleolus randomly, and those, with affinity to constitutive nucleolar components, are retained. It has been suggested that NoLSs act as retention signals rather than as classical targeting or transport signals [27,34]. It was possible to target the green fluorescent protein (GFP) into the GC of the nucleoli using sequences interacting with the acidic domains of B23/NPM [35].

Within the last few years, increasing evidence has revealed that viruses require the nucleus and in particular the nucleolus for their replication [36]. In addition to N-terminal NLS1, the C-terminus of the NS1 proteins of $\mathrm{H} 3 \mathrm{~N} 2$ and H2N2 influenza viruses have another NLS, NLS2, which also functions as a NoLS and targets the protein into the nucleolus [37]. A functional NLS2/NoLS of the Udorn $\mathrm{H} 3 \mathrm{~N} 2$ virus NS1 protein required basic arginine/lysine residues at its $\mathrm{C}$-terminal end for nucleolar localization to take place [37]. Seasonal H1N1 virus NS1 proteins seem to lack these C-terminal basic residues. In addition, the C-terminal end of the H5N1 (avian virus) and H1N1pdm09 NS1 protein resembles those of the seasonal $\mathrm{H} 1 \mathrm{~N} 1$ subtype viruses or have a 15 amino acid truncation, respectively, and are thus likely to lack the C-terminal NLS2/NoLS. Murayama and co-workers identified nucleolin, an abundant nucleolar protein as a novel NS1-binding protein [38]. By laser confocal microscopy, they observed the co-localization of NS1 with nucleolin most clearly in the nucleoli, suggesting that NS1 was interacting with nucleolin during the infection [38].

Here, we show that the NS1 protein of the human $\mathrm{H} 3 \mathrm{~N} 2$ virus interacts primarily via the C-terminal NLS2/ NoLS and to a minor extent via the N-terminal NLS1 with the main nucleolar proteins, nucleolin, B23 and fibrillarin. Direct interactions were observed for nucleolin and fibrillarin but not with in vitro-translated B23. Using GFP-NS1 fusion proteins, we show that the nucleolar retention of the NS1 protein is determined by its C-terminal NLS2/NoLS in vivo. Confocal laser microscopy results show that the NS1 protein colocalizes with nucleolin in nucleolus and nucleoplasm and with B23 and fibrillarin in nucleolus in influenza A/Udorn/72 virus-infected A549 cells.

\section{Results}

NS1 proteins, containing a C-terminal NLS2/NoLS, are targeted into the nucleoli in H3N2 subtype influenza $A$ virus-infected A549 cells

We have previously shown that the NS1 protein of the H3N2 subtype influenza A viruses contain a C-terminal NLS2/NoLS (Figure 1A) that targets the protein into the nucleoli in virus-infected cells [37]. To further confirm this observation, we infected A549 cells with wild type recombinant $\mathrm{H} 1 \mathrm{~N} 1$ subtype $\mathrm{A} / \mathrm{WSN} / 33$ and $\mathrm{A} / \mathrm{WSN} / 33$ virus expressing the $1918 \mathrm{NS}$ gene (A/Brevig Mission/1/ 18 segm 8), H3N2 subtype A/Udorn/72, H1N1pdm09 subtype A/Fin/554/09 and avian H7N3 subtype A/mallard/Netherlands/12/00 viruses for nine h. After fixation of the cells, NS1 protein expression was detected using anti-NS1 protein-specific antibodies (Figure 1C). In general, all analyzed NS1 proteins were mainly observed to be localized in the cell nuclei. As an exception, the NS1 protein of the A/Udorn/72 virus was observed in the cell nucleus and enriched in nucleoli while a weaker nucleolar staining was seen in A/WSN/33 virus-infected cells (Figure 1C). The NS1 proteins of the recombinant A/WSN/33 (A/Brevig Mission/1/18 segm 8), A/mallard/ 


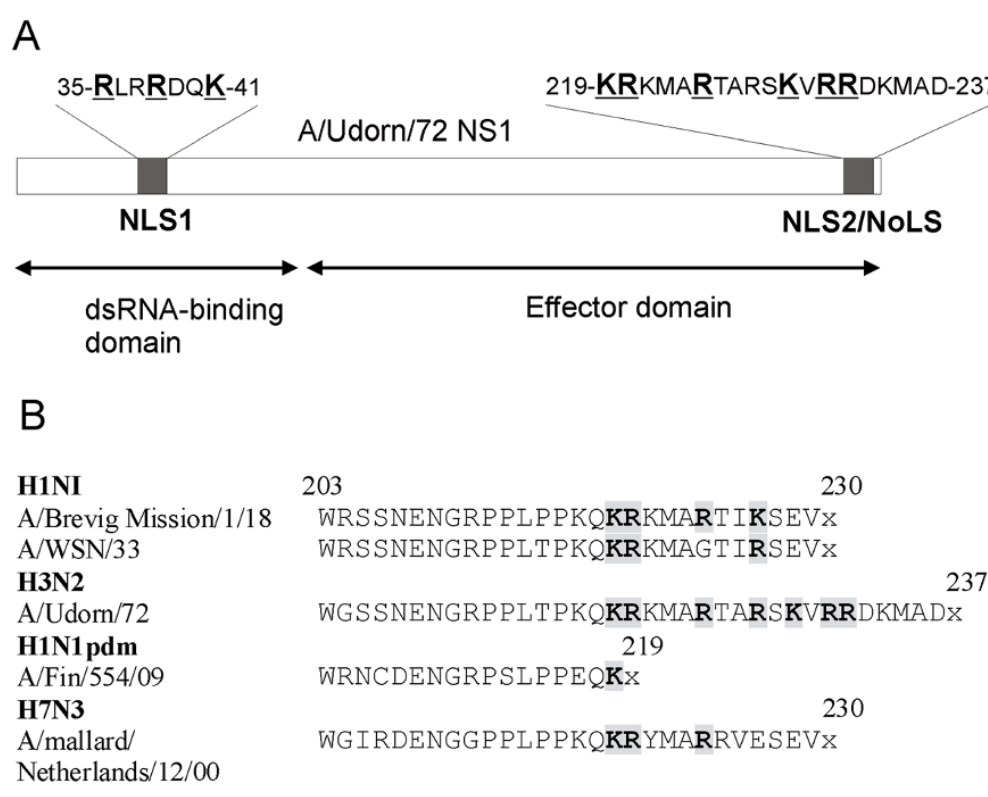

C

Anti-NS1

A/WSN/33/Brevig Mission A/WSN/33
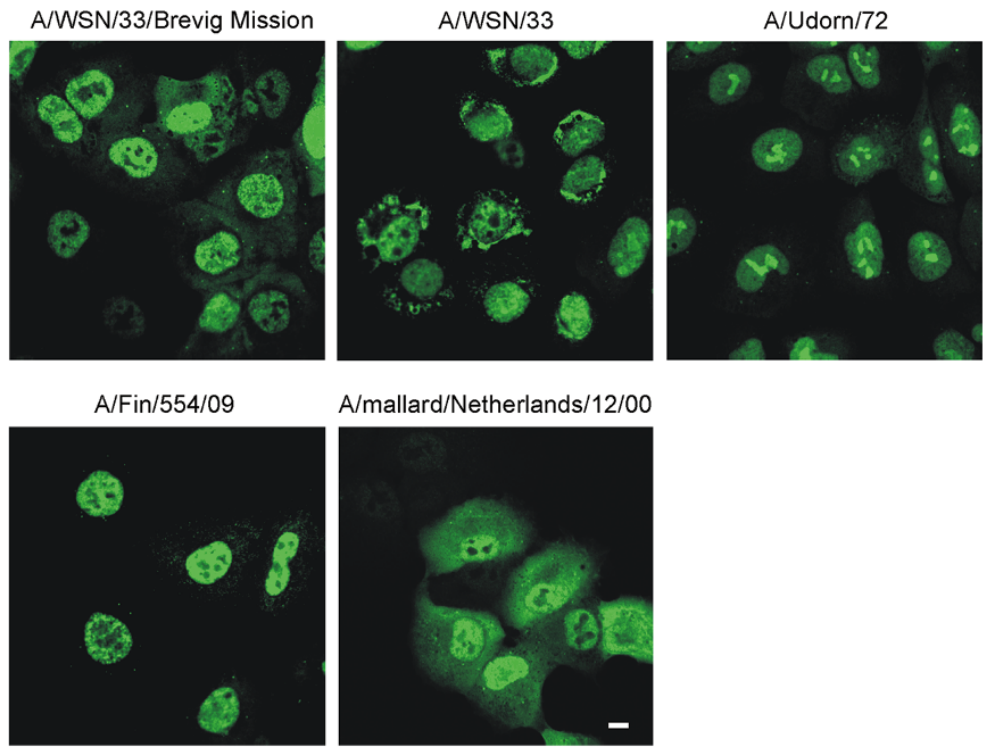

A/mallard/Netherlands/12/00

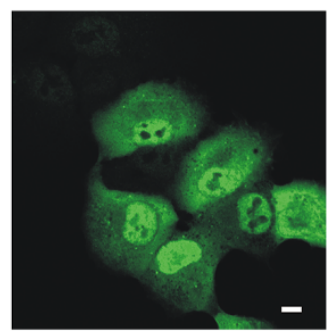

Figure 1 NS1 protein in H3N2 type influenza A viruses targets into the nucleolus in virus-infected A549 cells. (A) A schematic

representation of the intracellular targeting signals of the A/Udorn/72 virus NS1 protein. (B) Variations of putative C-terminal NLS2/NoLSs in selected influenza A virus NS1 proteins are presented. Critical amino acids 219, 220, 224, 227, 229, 231, and 232 that are involved in targeting the NS1 protein into the nucleus and nucleolus [37] are shown in boldface. (C) A549 cells grown directly on coverslips were infected with recombinant influenza A/WSN/33 (A/Brevig Mission/1/18 segm 8) or wt A/WSN/33 (H1N1), A/Udorn/72 (H3N2), A/Fin/554/09 (H1N1 pdm09) and A/Mallard/Netherlands/12/00 (H7N3) viruses (MOI 5) for $9 \mathrm{~h}$ as indicated in the figure. After fixation, the cells were stained with rabbit anti-NS1 and fluorescein isothiocyanate-labeled anti-rabbit immunoglobulins, followed by analysis with confocal laser microscopy. Bar, $5 \mu \mathrm{m}$.

Netherlands/12/00 and H1N1pdm09 A/Fin/554/09 viruses were mainly excluded from nucleoli, even though clear nucleolar staining was still detected in few cells.

NS1 protein can change its location over the time course of infection. NS1 is nuclear in the beginning and both nuclear and cytoplasmic at later stages of the infection [37]. Cytoplasmic translocation is mediated by a nuclear export signal (NES) [39]. Cellular localization emphasizes the specific functions of the NS1 protein in the cytoplasm, nucleus and nucleolus. 
The chimeric GFP-NS1 protein that contains the C-terminus of the H3N2 subtype influenza A/Udorn/72 virus is targeted into the nucleoli in transiently transfected HuH7 cells

Next, fragments of the NS1 genes encoding for amino acids $1-73$ and $157-237$ of the NS1 protein of A/ Udorn/72 virus, for amino acids $1-73$ and 157-230 of the NS1 protein of $\mathrm{A} / \mathrm{WSN} / 33$ virus and for amino acids 203-230 of the NS1 protein of A/Brevig Mission/1/18 virus were inserted into a GFP expression vector $\mathrm{pCMX-}$ SAH/Y145F and GFP-NS1 fragment fusion proteins were transiently expressed in $\mathrm{HuH7}$ cells (Figure 2). The $\mathrm{N}$-termini (amino acids 1-73) of the H3N2 and H1N1 subtype influenza virus NS1 proteins, containing the NLS1 (Figure 2A), efficiently targeted the fusion proteins into the cell nucleus but not to the nucleoli which appeared to remain negative (Figure $2 \mathrm{~B}$ and $\mathrm{C}$ ). The $\mathrm{C}$ terminal part (amino acids 157-237) of the NS1 protein of the H3N2 subtype influenza virus, containing the NLS2/NoLS, also targeted the fusion protein into the cell nucleus but, in addition, concentrated strongly in the nucleoli (Figure 2B). The mutation of several basic arginine $(\mathrm{R})$ and lysine $(\mathrm{K})$ residues to alanine $(\mathrm{A})$ of the NLS2/NoLS (K219A,R220A + R231A,R232A) abolished the accumulation of this fusion protein into the host cell nucleus and nucleoli and led to a localization of the fusion protein similar to that of GFP (Figure 2B). Similarly, the GFP-NS1 A/WSN/33 (amino acids 157-230) and GFP-NS1 A/Brevig Mission/1/18 (amino acids 203230) fusion proteins did not clearly accumulate neither in the nucleus nor in nucleoli and exhibited a localization rather comparable to that of the GFP alone (Figure 2C).

\section{The C-terminal NoLS of the influenza A/Udorn/72 NS1 protein binds to nucleolar proteins nucleolin, B23 and fibrillarin}

Next, we carried out pull-down experiments using A549 cell extracts to identify the nucleolar proteins that could interact with influenza A virus NS1 protein. In these experiments wt NS1 protein of the H3N2 subtype A/ Udorn/72 influenza virus was observed to interact with nucleolin, B23 and fibrillarin (Figure 3B). The 1918 H1N1 subtype A/Brevig Mission/1/18 virus NS1 protein was observed to interact with nucleolin and B23 and the H7N3 subtype A/mallard/Neatherlands/12/00 virus NS1 protein with $\mathrm{B} 23$ and fibrillarin but these interactions were weak (Figure $3 \mathrm{~B}$ ). Unfortunately, the expression levels of GST-NS1 A/Brevig Mission/1/18 and GST-NS1 $\mathrm{A} /$ mallard/Neatherlands/12/00 fusion proteins were much lower than that of GST-NS1 A/Udorn/72. Thus, the relative binding intensities of these proteins with nucleolar proteins could not be compared (Figure 3B). Previously, it has been suggested that the N-terminal
RNA-binding domain of the NS1 binds nucleolin [38]. To further confirm this observation in our experimental system, we used GST-NS1 A/Udorn/72 (amino acids 173) fusion protein (Figure 3A) in pull-down experiments and found a weak binding of nucleolin, B23 and fibrillarin to the N-terminal part of NS1. The binding was totally abolished by R38A and K41A substitution mutations to the RNA-binding domain, which are the critical amino acids that form the NLS1 of the NS1 protein (Figure 3B). Conversely, the GST-NS1 A/Udorn/72 (amino acids 203-237) fusion protein pulled-down the nucleolar proteins, nucleolin, B23 and fibrillarin at least as well as the wt NS1 protein did (Figure 3B) showing the predominant role of the C-terminus of the NS1 protein in the interactions of NS1 with nucleolin, B23 and fibrillarin. These bindings were totally abolished by K219A,R220A + R231A,R232A substitution mutations (Figure 3B) highlighting the importance of NLS2/NoLS sequences in the interaction with nucleolar proteins.

\section{The C-terminal NLS2/NoLS of the NS1 protein of the influenza $A / U d o r n / 72$ virus bound in vitro-translated nucleolin and fibrillarin but not in vitro-translated B23 in a GST pull-down experiment}

Next, to verify our previous binding results and to know whether the interactions between NS1 protein and nucleolar proteins occur directly or indirectly via other proteins, we carried out pull-down experiments using in vitro-translated $\left[{ }^{35} \mathrm{~S}\right]$-methionine-labeled nucleolin, B23 and fibrillarin. The procedure is described in the legend of Figure 4 and the GST-NS1 fusions were the same as in the experiments described above (Figure 3). The wt NS1 protein of the H3N2 subtype A/Udorn/72 influenza virus bound directly the in vitro-translated nucleolin and fibrillarin but not the in vitro-translated B23 (Figure 4). Instead, the wt NS1 protein of the H1N1 subtype A/Brevig Mission/1/18 virus bound only weakly nucleolin and fibrillarin, while the wt NS1 protein of the H7N3 subtype mallard/Neatherlands/12/00 virus showed a weak binding to fibrillarin but not to the other tested nucleolar proteins (Figure 4). The GST-NS1/Udorn/72 (amino acids 1-73) fusion protein clearly pulled-down nucleolin and fibrillarin showing the role of the $\mathrm{N}$ terminus of the NS1 protein of the H3N2 subtype A/ Udorn/72 influenza virus in these interactions. The interactions were totally abolished by R38A and K41A substitution mutations (Figure 4) and therefore the interactions are most likely dependent on NLS1 of the NS1 protein. The GST-NS1 A/Udorn/72 (amino acids 203-237) fusion protein bound nucleolin and fibrillarin as efficiently as the wt NS1 protein (Figure 4) showing the crucial role played by the C-terminus of the NS1 protein in these direct interactions. This binding was totally abolished by K219A,R220A + R231A,R232A 


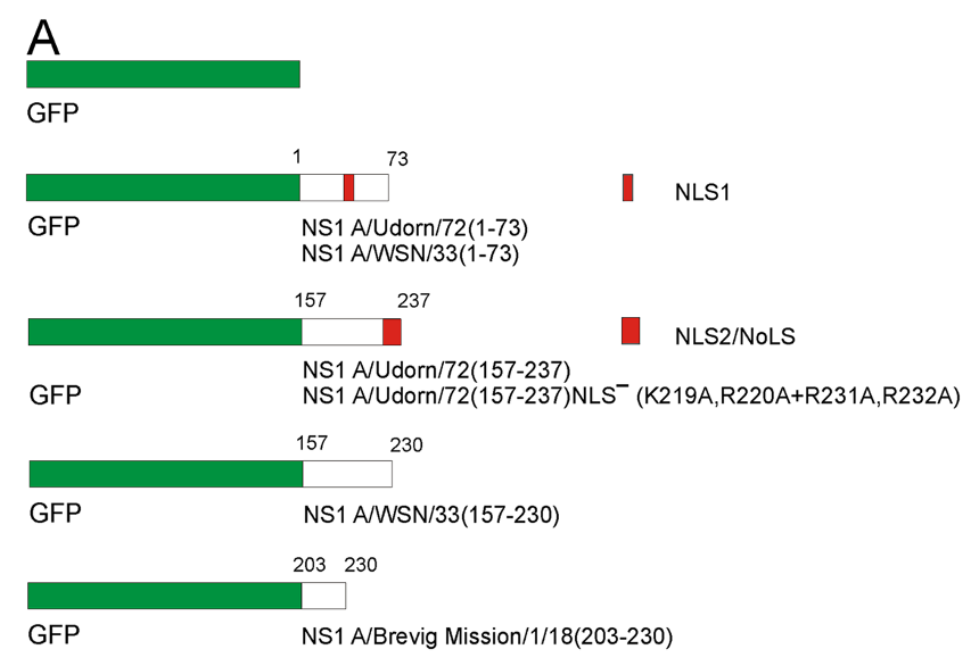

\section{B GFP-NS1A}

H3N2 viruses

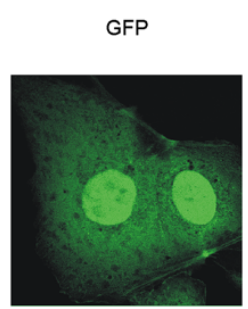

GFP-NS1 A/Udorn/72 GFP-NS1 A/Udorn/72
C-t, aa 157-237 GFP-NS1 A/Udorn/72 NLS $\mathrm{N}-\mathrm{t}$, aa $1-73$

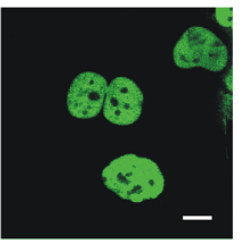

${ }^{34}$ DRLRRDQKKSLR ${ }^{44}$

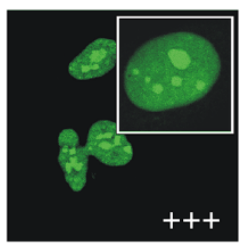

$Q^{218}$ KRKMARTARSSKV RRDKMAD ${ }^{237}$
C-t, aa $157-237$

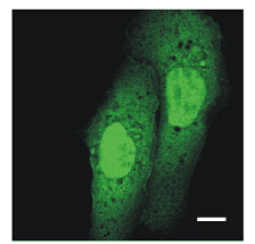

$Q^{218} \mathrm{AAKMARTARS} \underline{K V}$ AADKMAD 237

\section{GFP-NS1A}

H1N1 viruses

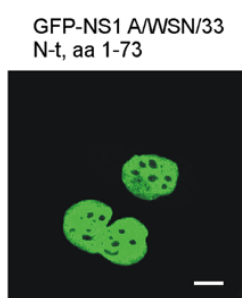

${ }^{34} \mathrm{DRLRRDQKKSLR}{ }^{44}$

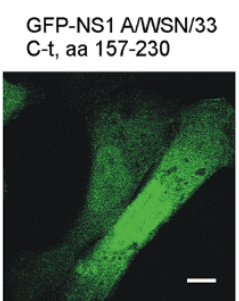

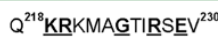

GFP-NS1 A/Brevig Mission/1/18 C-t, aa 203-230

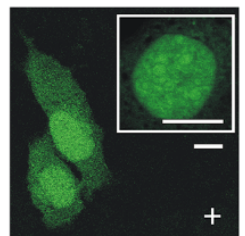

$Q^{218} \underline{K R} K M A \underline{R} T I \underline{K S} \underline{\underline{E}} \mathrm{~V}^{230}$

Figure 2 The C-terminal end of the NS1 protein in H3N2 type influenza A viruses encode for a functional NoLS. (A) The N- and C-terminal fragments of the NS1 genes, encoding for amino acids 1-73 and 157-237 in A/Udorn/72, amino acids 1-73 and 157-230 in A/WSN/33 and amino acids 203-230 in A/Brevig Mission/1/18, were inserted into the GFP expression vector pCMX-SAH/Y145F to express GFP-NS1 fusion proteins. Mutations in the C-terminal NLS2/NoLS of A/Udorn/72 virus NS1 protein were performed as described in Materials and Methods. Red boxes indicate the positions of N-terminal NLS1 and C-terminal NLS2/NoLS in NS1 protein. (B) HuH7 cells were transiently transfected with GFP, GFP-NS1 fusion and GFP-NS1 fusion mutant (K219A,R220A + R231A,R232A) A/Udorn/72 gene constructs, as indicated in the figure, for $48 \mathrm{~h}$. The intensity of nucleolar localization was scored by immunofluorescence microscopy as no nucleolar staining $(-)$ or weak (+), moderate $(++)$ or strong $(+++)$ nucleolar staining. Critical basic amino acids involved in nuclear/nucleolar targeting are marked in boldface and underlined. Mutated amino acids (K219A,R220A + R231A,R232A) are marked in red. (C) HuH7 cells were transiently transfected with GFP and the GFP-deletion gene constructs of NS1 A/WSN/33 and NS1 A/Brevig Mission/1/18 for $48 \mathrm{~h}$ as indicated in the figure. Critical and mutated amino acids are

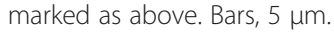

substitution mutations (Figure 4) of the previously identified NLS2/NoLS of the Udorn virus NS1 protein [37]. We can therefore conclude that the NLS2/NoLS is implicated in direct interactions between the NS1 protein with nucleolin and fibrillarin.
The NS1 protein colocalized with nucleolin and to a minor extent with B23 and fibrillarin in influenza A/ Udorn/72 virus-infected A549 cells

Next, we analyzed the colocalization of H3N2 subtype influenza A virus NS1 protein with nucleolin, B23 and 


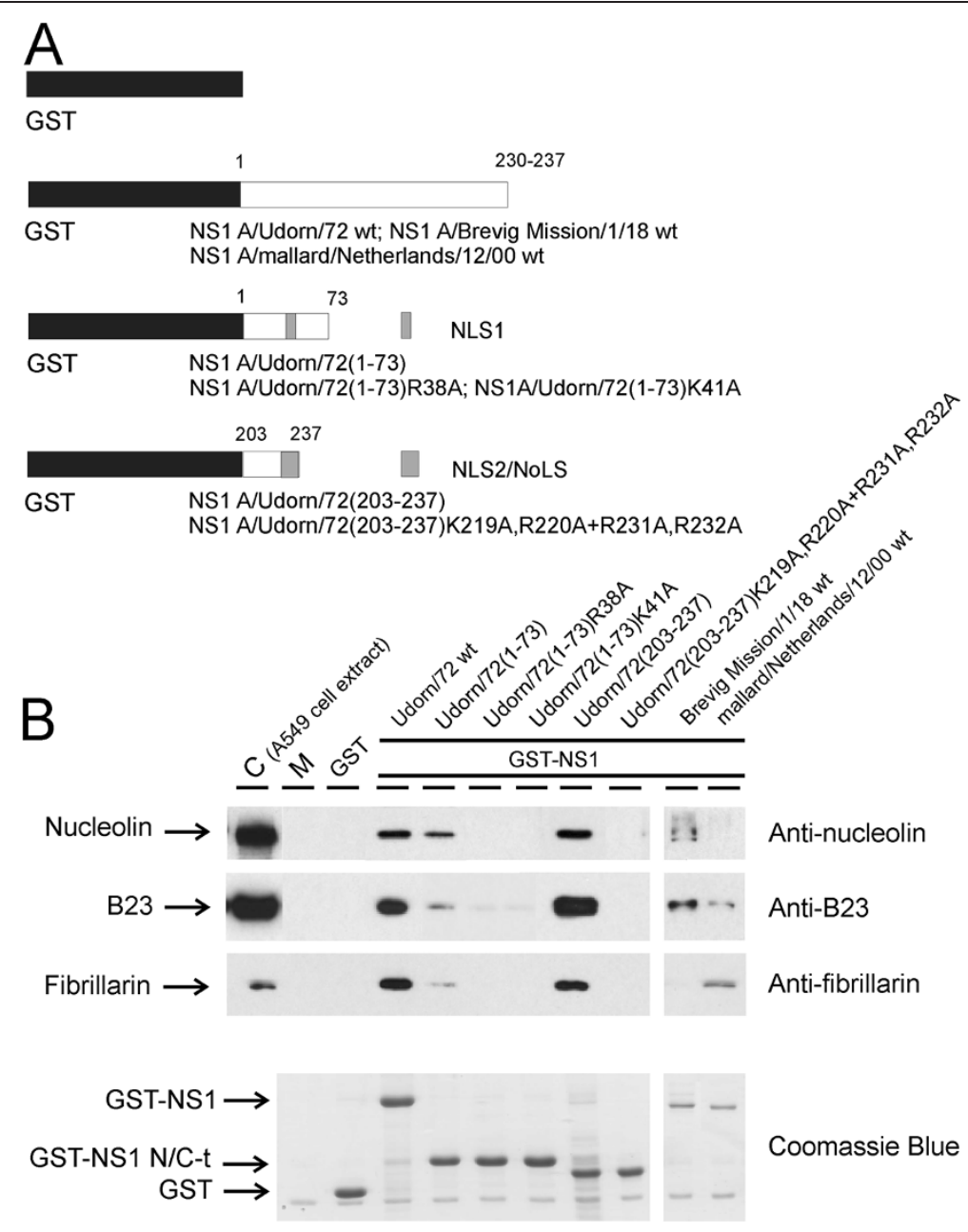

Figure 3 The C-terminal NoLS of the NS1 protein in H3N2 subtype influenza A viruses binds nucleolar nucleolin, B23 and fibrillarin in a GST-NS1 pull-down experiment. (A) N- and C-terminal fragments of the NS1 gene encoding for amino acids 1-73 and 203-237 in A/Udorn/72 and wt genes, encoding for amino acids 1-237 in A/Udorn/72 and amino acids 1-230 in A/Brevig Mission/1/18 and in A/Mallard/Netherlands/12/ 00, were inserted into the GST expression vector pGEX $2 \mathrm{~T}(+)$ to express GST-NS1 fusion proteins. Mutations were created into the $\mathrm{N}$-terminal NLS1 and C-terminal NLS2/NoLS in the A/Udorn/72 virus NS1 protein are as indicated in the figure. (B) The cell extracts of cultured A549 cells were prepared, and proteins in cell extracts were allowed to bind to E. coli-expressed and Sepharose-immobilized GST, GST-NS1 A/Udorn/72 wt, GST-NS1 A/Udorn/72(1-73), GST-NS1 A/Udorn/72(1-73)R38A, GST-NS1 A/Udorn/72(1-73)K41A, GST-NS1 A/Udorn/72(203-237), GST-NS1 A/Udorn/ 72(203-237)K219A,R220A + R231A,R232A, GST-NS1 A/Brevig mission/1/18 wt and GST-NS1 mallard/Netherlands/12/00 wt at $+4{ }^{\circ} \mathrm{C}$ for $1 \mathrm{~h}$. Sepharose-bound proteins were dissolved in Laemmli sample buffer and separated on $8 \%$ SDS-PAGE. Western blots were stained with anti-nucleolin, -B23 and -fibrillarin immunoglobulins. As a control, A549 cell extract, containing $10 \mu \mathrm{g}$ of proteins, was stained in lane C. $\mathrm{M}$ indicates the Sepharose matrix-bound proteins. A similar gel was also stained with Coomassie Brilliant Blue to visualize the amount of Sepharose-immobilized GST and GST-NS1 fusion proteins.

fibrillarin (Figure 5). The procedure is described in the legend of Figure 5. The strongest colocalization was observed between NS1 and nucleolin as evidenced by the merge of green and red signals visible in yellow in nucleoplasm and nucleolus. On the contrary, the colocalization of the NS1 protein with fibrillarin and B23 was mainly observed in the nucleolus (yellow in the merge images). The next step was the quantification of the relative distribution of both viral and nucleolar proteins in the nuclei. The signals were measured using ImageJ software in 3 groups of 30 cells, in which GFP-NS1 is expressed and either B23, or fibrillarin or nucleolin was detected by antibodies. The quantification was also performed on 30 control (CTR) cells not expressing NS1 for each nucleolar proteins. The fluorescence intensity was measured in the nucleoplasm and nucleoli of each cell (green and red fluorescence for cells expressing NS1 and red fluorescence for control cells) and was normalized to the mean nuclear fluorescence value to compare the concentration of B23, nucleolin and fibrillarin respectively very abundant, abundant and less abundant nucleolar proteins and the distribution of NS1 in each 


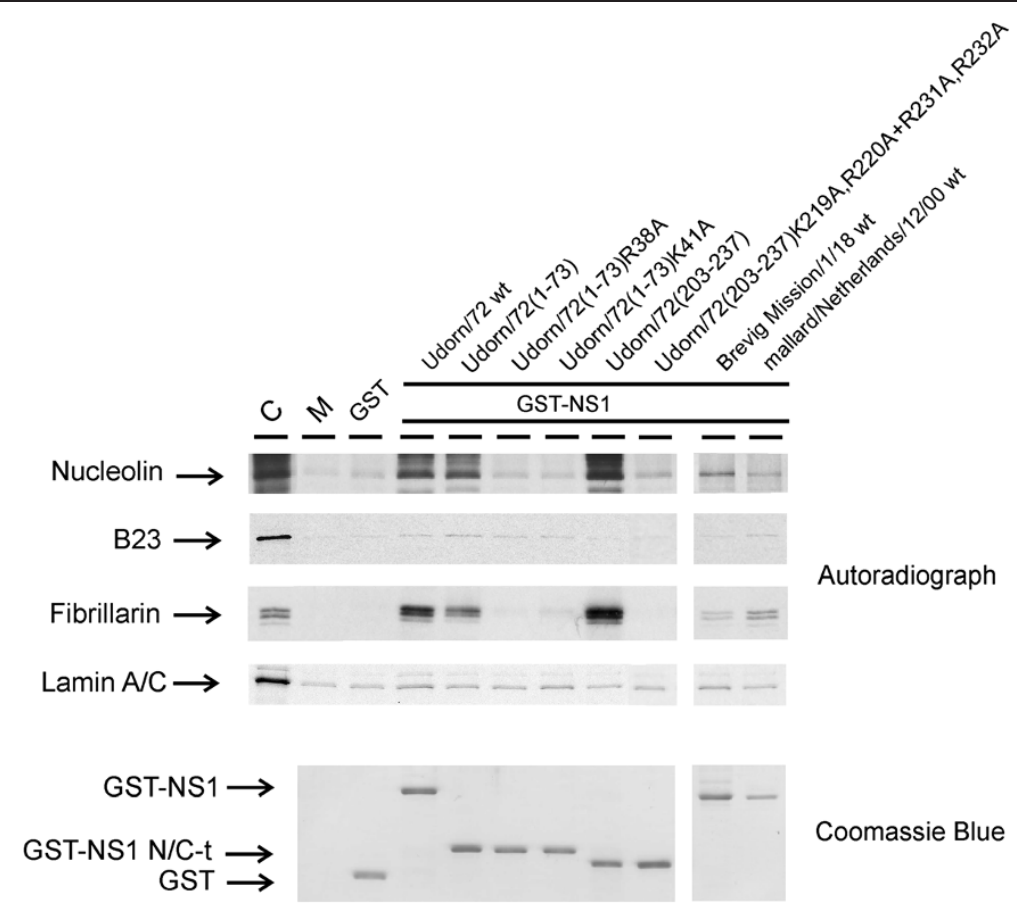

Figure 4 The C-terminal NoLS of the NS1 protein in the H3N2 subtype influenza A viruses binds in vitro-translated nucleolar nucleolin and fibrillarin in a GST pull-down experiment. $\left[{ }^{35} \mathrm{~S}\right.$ ]-labeled and in vitro-translated nucleolin, B23, fibrillarin and, as a control, lamin A/C were allowed to bind to E. coli-expressed and Sepharose-immobilized GST, GST-NS1 A/Udorn/72 wt, GST-NS1 A/Udorn/72(1-73), GST-NS1 A/Udorn/72 (1-73)R38A, GST-NS1 A/Udorn/72(1-73)K41A, GST-NS1 A/Udorn/72(203-237), GST-NS1 A/Udorn/72 (203-237)K219A,R220A + R231A,R232A, GSTNS1 A/Brevig mission/1/18 wt and GST-NS1 A/mallard/Netherlands/12/00 wt at $+4{ }^{\circ} \mathrm{C}$ for $1 \mathrm{~h}$. Sepharose-bound proteins were dissolved in Laemmli sample buffer, separated on $8 \%$ SDS-PAGE and autoradiographed. Input (lane C) was 1:10 of the amount of $\left[{ }^{35}\right.$ S]-labeled protein that was used in the binding experiment. M indicates the Sepharose matrix-bound proteins. A similar gel was also stained with Coomassie Blue to visualize the amount of Sepharose-immobilized GST and GST-NS1 fusion proteins.

group. The quantification indicated that the amount and distribution of NS1 is quite similar in the NS1-B23, NS1-fibrillarin, or NS1-nucleolin cells (Figure 5B) indicating that the expression of the NS1 protein is comparable in each group. The relative concentration of B23 in nucleoli in the presence of NS1 is high compared to the nucleoplasm but only half of that of the control cells (Figure 5B) suggesting a reduced relative concentration of B23 in nucleoli in the presence of NS1. The relative concentration of fibrillarin in the presence of NS1 is higher in nucleoli than in nucleoplasm but its relative concentration in the nucleoplasm is two-fold higher as compared to the control cells (Figure 5B). This could be due to the modification of the nuclear traffic of fibrillarin. The same relative distribution was observed for nucleolin and NS1 (Figure 5B) that is in accordance with our demonstration of the interaction between these proteins (Figures 3 and 4). It is possible that this interaction modifies the traffic of nucleolin in the cell because the relative nucleolar amount is higher in the control cells than in presence of NS1 (Figure 5B).

To analyze the relative re-distribution of the nucleolar proteins in the presence of NS1, the relative intensities of nucleolus/nucleoplasm ratios for both NS1 and nucleolar proteins was compared in each cell. The ratio for NS1/B23 is 0.19 , for NS1/fibrillarin it is 0.77 and for NS1/nucleolin it is 1.02 (Table 1 ). The ratios clearly demonstrate that the relative distribution of nucleolin and NS1 are similar in nucleolus and nucleoplasm in each cells (ratio 1) in contrast to fibrillarin and B23 (ratios 0.77 and 0.19 respectively), which show relatively higher amounts in the nucleoli than NS1. This analysis of the relative distribution of NS1 and the nucleolar proteins indicates a differential effect probably related to their function. It is interesting to note that fibrillarin is involved at the early stage of rRNA processing, B23 at late stage and nucleolin at different stages of rRNA processing.

High expression level of the HIV-1 Rev protein inhibited the nucleolar targeting of the H3N2 subtype influenza A virus GFP-NS1 protein fusion (amino acids 203-237)

Previously, it has been shown that HIV-1 Rev protein targets into the nucleolus [40] and binds to nucleolar B23 [41]. In order to further characterize NS1 nucleolar binding structures, we coexpressed the GFP-NS1 A/ 


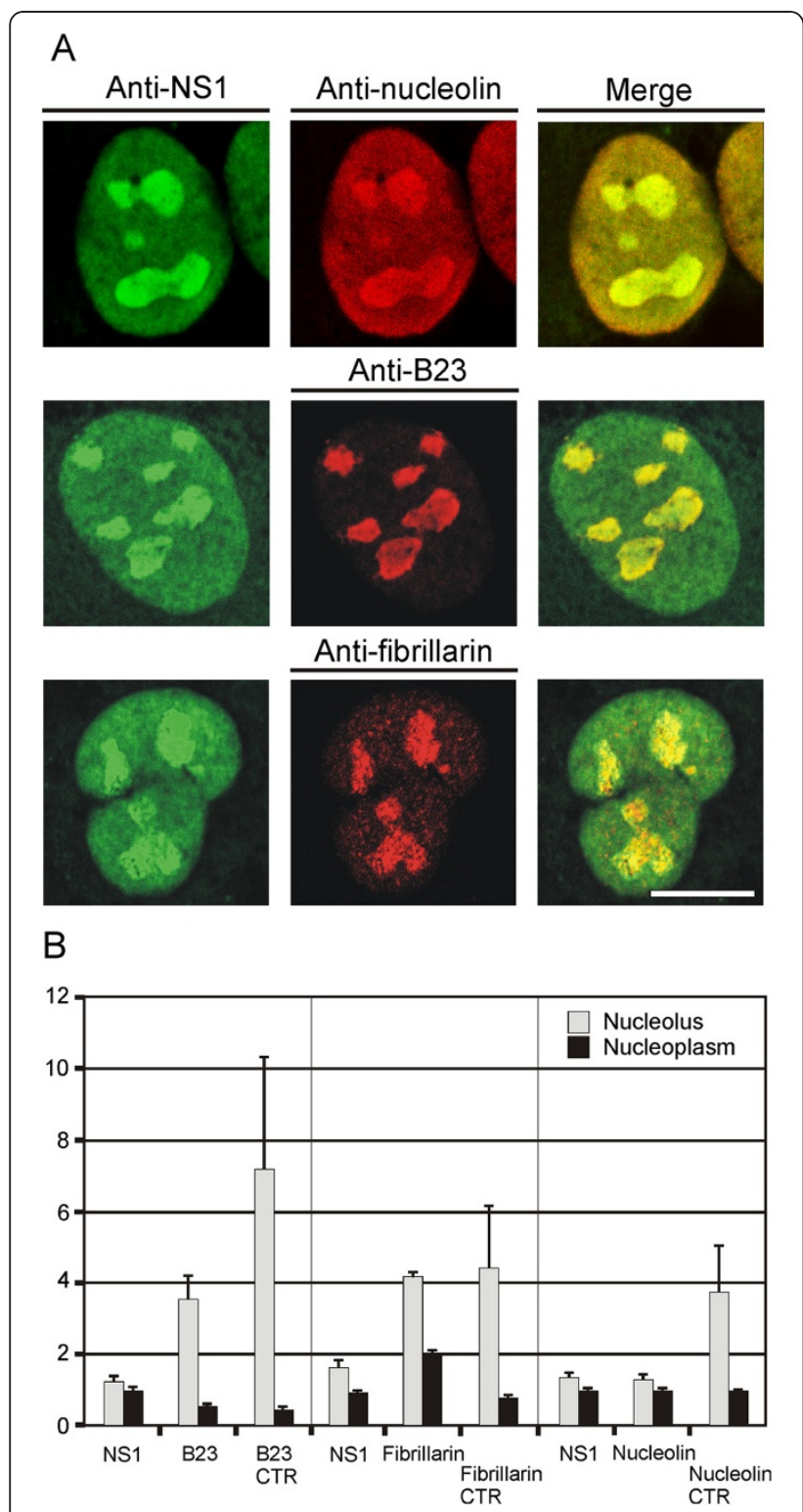

Figure 5 NS1 protein of the H3N2 subtype influenza A virus colocalizes with nucleolin in the nucleolus and nucleoplasm and with B23 and fibrillarin in the nucleolus in influenza A/ Udorn/72 virus-infected $\mathbf{A} 549$ cells. (A) A549 cells were infected with influenza A/Udorn/72 wt viruses (MOI 5) for eight hours, fixed with $3 \%$ paraformaldehyde and stained with rabbit or guinea pig anti-NS1 immunoglobulins, followed by fluorescein isothiocyanatelabeled goat anti-rabbit or anti-guinea pig immunoglobulins. To detect protein co-localization, cells were double-stained with mouse anti-nucleolin and anti-B23 or rabbit anti-fibrillarin immunoglobulins, followed by Rhodamine Red-X-labeled goat anti-mouse or antirabbit immunoglobulins, respectively. The colocalization of proteins was visualized with confocal laser microscopy. Only the nuclei of the cells are presented. Bar, $5 \mu \mathrm{m}$. (B) The relative distribution of both viral and nucleolar proteins in the nuclei, as illustrated in A, is presented. The relative intensity of fluorescence in the nucleolus and nucleoplasm was quantified by ImageJ software (mean of 30 cells in each case). The quantification was also performed on 30 control (CTR) cells not expressing NS1 for each nucleolar protein.
Table 1 The relative re-distribution of nucleolar proteins in the presence of NS1

\begin{tabular}{lll}
\hline Ratio & Ratio & Ratio \\
NU/NCP & NU/NCP & NS1/Nucleolar protein \\
\hline NS1 & B23 & 0.19 \\
1.36 & 8.89 & \\
NS1 & Fibrillarin & 0.77 \\
1.80 & 2.10 & \\
NS1 & Nucleolin & 1.02 \\
1.44 & 1.43 & \\
\hline
\end{tabular}

The relative intensities of nucleolus/nucleoli ratios for both NS1 and nucleolar proteins is compared in each cell. Quantification was done by ImageJ software (mean of 30 cells in each case). NU: nucleolus; NCP: nucleoplasm.

Udorn/72 (amino acids 203-237) fusion protein and the HIV-1 Rev protein and analyzed their possible nucleolar colocalization. The procedure is described in the legend of Figure 6. In this experiment, cells, expressing low, medium or high amounts of nucleolar HIV-1 Rev protein, were selected by the relative intensity of fluorescent light. 30 cells in all three groups were examined. As shown in Figure 6, the GFP-NS1( 203-237) fusion protein and HIV-1 Rev protein completely colocalized in the nucleolus. Interestingly, a high expression level of HIV-1 Rev protein totally displaced the GFP-NS1 protein fusion from the nucleoli to the nucleus. The phenomenon was clearly seen in all cells expressing high level of HIV-1 Rev protein. This further indicates that NS1 protein, and specifically its C-terminal NLS2/NoLS domain, has a strong nucleolar retention signal that is likely binding to similar nucleolar proteins/structures as HIV-1 Rev protein does.

\section{Discussion}

Many different viruses target the nucleolus to disrupt host-cell functions and to recruit cellular proteins to aid in virus replication. As the primary site of the replication of positive-strand RNA viruses and most negative-strand RNA viruses is the cytoplasm, the reason for RNA viruses to target nuclear structures is not immediately obvious. However, among RNA viruses, influenza virus is an exception, since all the essential viral replication events take place in the nucleus.

We have previously shown that the NS1 protein of the H3N2 subtype influenza A virus contains a C-terminal NLS2/NoLS that efficiently targets the protein into the nucleoli in virus-infected cells [37]. Murayama and coworkers identified the nucleolar protein, nucleolin, as a novel NS1-binding protein [38]. They also suggested that the N-terminal part of the NS1 protein was responsible for this binding, as judged by a GST pull-down assay with the GST-fused functional domains of NS1. By laser confocal microscopy, they observed that NS1 colocalized 


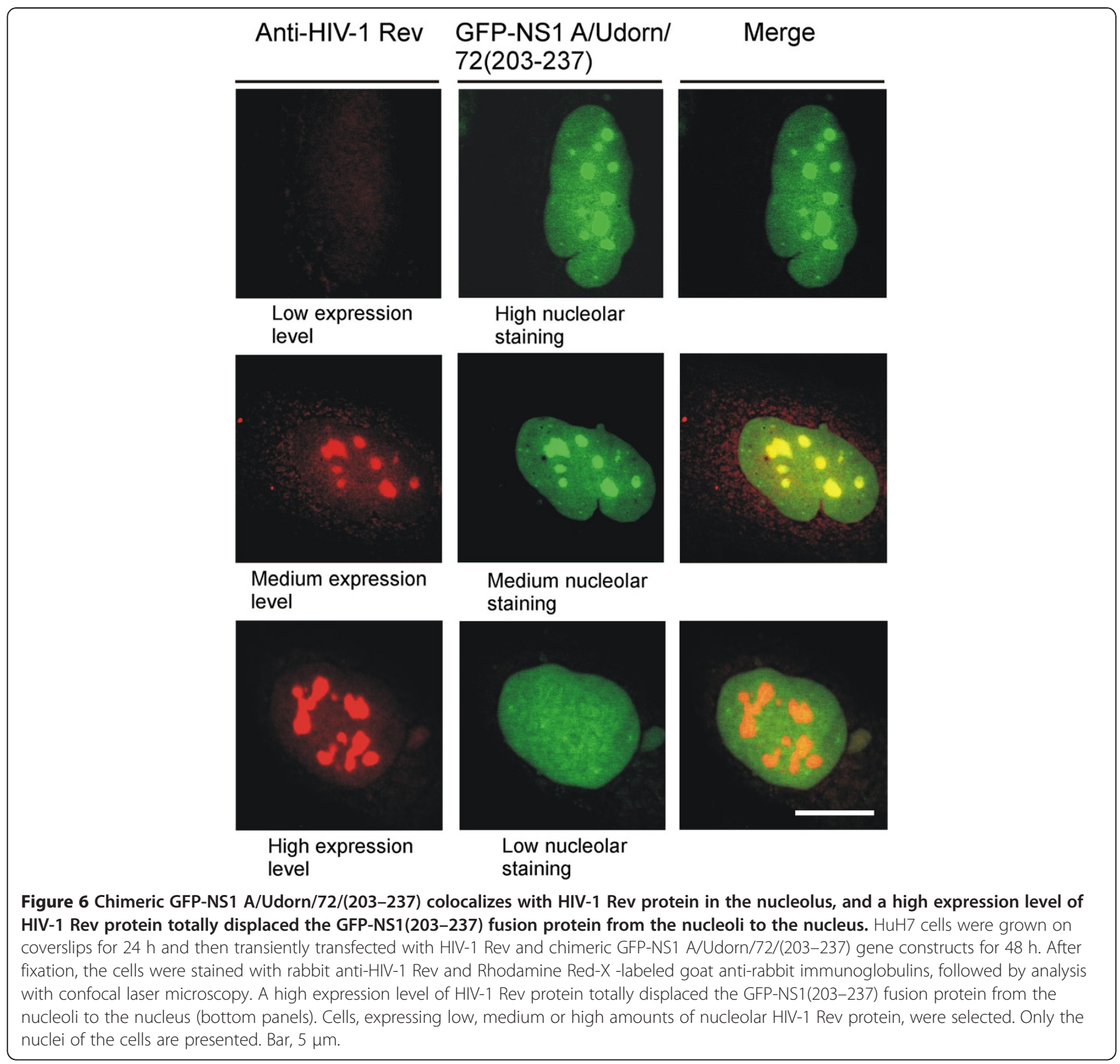

with nucleolin most clearly in the nucleoli, indicating that NS1 was interacting with nucleolin during the infection [38].

In the present study, instead, we show that the NS1 protein of the human $\mathrm{H} 3 \mathrm{~N} 2$ subtype influenza A virus can interact, primarily via its C-terminal NoLS, with the main nucleolar proteins, nucleolin, B23 and fibrillarin in vitro. Using GFP-NS1 fusion proteins, we observed that the N-terminal part of both the H3N2 and H1N1 subtype influenza NS1 protein, containing a functional NLS1, targeted the chimeric proteins into the cell nucleus but not to the nucleolus (Figure $2 \mathrm{~B}$ and $\mathrm{C}$ ). However, only the C-terminus of the NS1 protein of the H3N2 subtype A influenza virus, containing a functional
NLS2/NoLS, targeted the chimeric protein into the cell nucleus and nucleoli (Figure $2 \mathrm{~B}$ and $\mathrm{C}$ ). Mutations in the NLS2/NoLS abolished both the nuclear and nucleolar targeting (Figure 2B). A chimeric GFP-NS1 A/ Brevig Mission/1/18(203-230) protein was only faintly targeted into the cell nucleus and nucleolus (Figure 2C). These results are in agreement with our previous results showing that all types of influenza A virus NS1 proteins have an N-terminal NLS1, while H3N2 subtype viruses also have an additional NLS, a C-terminal NLS2, which also functions as a NoLS [37].

As mentioned above, Murayama and co-workers showed that the N-terminal RNA-binding domain of the NS1 protein was responsible for the binding to nucleolin 
[38]. Using GST-NS1 A/Udorn/72(1-73) fusion protein construct and A549 cell extracts, we were also able to see a weak binding of nucleolin, B23 and fibrillarin to the N-terminal part of a chimeric NS1 protein (Figure 3). The binding was abolished by R38A and K41A substitution mutations to the RNA-binding domain of the NS1 protein (Figure 3B). The same amino acids are also critical for the importin $\alpha$-binding and nuclear translocation of NS1 protein via the nuclear transport machinery [37]. Instead, the C-terminal part of the NS1 protein in the chimeric construct GST-NS1/A/Udorn/72(203-237) bound nucleolin, B23 and fibrillarin as well as the wt NS1 protein did (Figure 3B). This binding was totally abolished by K219A,R220A + R231A,R232A substitution mutations (Figure 3B), indicating the NLS2/NoLS to be primarily responsible for the binding of NS1 to nucleolar proteins.

The signals that govern the nucleolar localization and retention of different proteins are not well defined. The motifs involved are usually rich in arginine and lysine residues, however, there is no obvious consensus sequence or structure. Proteins that localize in the nucleolus can also have nuclear import and export motifs. It is unclear whether nucleolar proteins are specifically localized, targeted, accumulated or just retained in the nucleolus and consequently the sequences associated with the nucleolar localization have thus been designated as nucleolar targeting signals and/or nucleolar retention signals. In many cases, proteins that localize in the cytoplasm and in the nucleus and/or nucleoli contain multiple signals that determine their subcellular localization. This highlights the difficulty in identifying truly functional NoLSs. Moreover, proteins that localize in the nucleoli must first be imported into the nucleus and therefore they likely possess both NLS and NoLS whose sequences may overlap (Reviewed in [29].

Our previous [37] and present data clearly shows that the nucleolar retention of the H3N2 subtype influenza A virus NS1 protein is mediated primarily by its Cterminal NLS2/NoLS. However, the N-terminal NLS1 may also mediate weak nuclear retention of NS1 protein, since the H1N1pdm NS1 protein was weakly localized into the nucleoli, even if it lacked the C-terminal NLS2/ NoLS due to a stop codon at position 220 (Figure 1). There may also be viral species-specific differences, since the 230-amino-acid-long NS1 of the avian A/mallard/ Netherlands/12/00 virus completely failed to target into the nucleoli (Figure 1).

Nucleoli are compact structures, and thus it was quite expected that all three major nucleolar proteins coprecipitated with the H3N2 virus NS1 protein in GST pull-down experiments. However, in vitro-translated nucleolar proteins showed that nucleolin and fibrillarin specifically bound to the C-terminal part of the NS1 protein in a manner similar to that seen with A549 cell extracts (compare Figures 3 and 4). Instead, in vitrotranslated B23 did not bind to the NS1 protein suggesting that this protein has no intrinsic binding ability to NS1. However, it coprecipitated with other nucleolar proteins in GST pull-down experiments (Figure 4). It is also possible that in vitro-translated B23 is misfolded or requires additional posttranslational modifications, such as phosphorylation for the NS1 interaction to take place.

Laser confocal microscopy showed a clear colocalization of NS1 with nucleolin, B23 and fibrillarin, indicating that NS1 was interacting with these proteins during the virus infection (Figure 5A). The HIV-1 Rev protein has previously been shown to localize into the nucleolus (reviewed in [42]). Like many viral proteins that target into the nucleolus, Rev has also been shown to contain a functional NoLS [43]. In the nucleolus, HIV-1 Rev protein binds to nucleolar B23 [41] and localizes to the combined regions of the dense fibrillar component and the granular component. To further identify the interaction partners of NS1 in the nucleolus, we analyzed nucleolar co-localization of the GFP-NS1 A/ Udorn/72/(203-237) and HIV-1 Rev proteins. GFP-NS1 A/Udorn/72/(203-237) and HIV-1 Rev proteins colocalized in the nucleolus, and high expression level of the HIV-1 Rev protein totally displaced the chimeric GFPNS1(203-237) protein from the nucleolus. This may indicate that these proteins are binding to similar structures within the nucleolus or that all nucleolar proteins have a very tight interaction with each others.

Further analysis of the role of the nuclear retention of the NS1 protein during influenza virus infection is needed. The fact that viral proteins contain NoLSs is an indication that viruses have evolved specific nucleolar functions. There is emerging evidence that the disruption of the nuclear or nucleolar trafficking by some positive-stranded RNA virus proteins may have a role in viral pathogenesis.

\section{Conclusions}

The present study shows that the NS1 protein of the human H3N2 subtype virus interacts in vitro primarily via its C-terminal NLS2/NoLS and to a minor extent via its N-terminal NLS1 with the nucleolar proteins, nucleolin and fibrillarin. Using chimeric green fluorescence protein (GFP)-NS1 fusion constructs, we show that the nucleolar retention of the NS1 protein is determined by its C-terminal NLS2/NoLS in vivo. Confocal laser microscopy analysis shows that the NS1 protein colocalizes with nucleolin in nucleoplasm and nucleolus and with B23 and fibrillarin in the nucleolus of influenza A/ Udorn/72 virus-infected A549 cells. Since some viral proteins contain NoLSs, it is likely that viruses have 
evolved specific nucleolar functions. It is thus likely that the nucleolar targeting function of NS1 protein plays a role in the pathogenesis of human influenza A viruses that, undoubtedly, deserves further studies.

\section{Methods \\ Cells}

Human A549 lung carcinoma cell line (ATCC, CCL 185) was maintained in a continuous culture in minimum Eagle's medium- $\alpha$ (Invitrogen Corp., Carlsbad, CA, USA) supplemented with $0.6 \mu \mathrm{g} / \mathrm{ml}$ penicillin, $60 \mu \mathrm{g} / \mathrm{ml}$ streptomycin and 10\% fetal calf serum (Integro, BV, Dieren, The Netherlands). Human hepatocellular carcinoma HuH7 [44] cells were maintained in minimum Eagle's medium- $\alpha$ with supplements as above.

\section{Generation of reverse genetics A/WSN/33 (A/Brevig Mission/1/18 segm 8 ) virus}

Reverse genetics in the A/WSN/33 H1N1 background [45] was performed using a $\mathrm{pHH} 21$ vector containing a wild-type synthetic gene fragment encoding the A/Brevig Mission/1/18 NS gene [17]. Viruses were propagated using Madin-Darby canine kidney (MDCK) cells [46].

\section{Viruses and infections}

A549 cells, grown on 6-well plates or on glass coverslips on 24-well plates, were infected with the following viruses: A/Udorn/72 (H3N2), A/WSN/33 (H1N1), A/ WSN/33 (A/Brevig Mission/1/18 segm 8) (H1N1), A/Fin/ 554/09 (H1N1pdm09) and A/mallard/Netherlands/12/ 2000 (H7N3). Virus stocks were cultivated in eightday-old embryonated chicken eggs and stored at $-70{ }^{\circ} \mathrm{C}$. The hemagglutination titers of the stock viruses ranged from 64 to 256 , and the infectivity of the virus stocks in A549 cells was $1-4 \times 10^{7} \mathrm{pfu} / \mathrm{ml}$. The multiplicity of infection (MOI) used in the experiments varied from 0.5 to $5 \mathrm{pfu} / \mathrm{cell}$.

\section{Antibodies}

In Western blot analysis mouse monoclonal antinucleolin (anti-C23; sc-8031; 1:1000 dilution; Santa Cruz Biotechnology, Santa Cruz, CA, USA), mouse monoclonal anti-B23 (sc-32256; 1:2000 dilution; Santa Cruz Biotechnology) and rabbit polyclonal anti-fibrillarin (\#2639; 1:200 dilution; Cell Signaling Technology, Inc., Beverly, MA, USA) immunoglobulins were used. Secondary HRP-conjugated goat anti-mouse and goat anti-rabbit immunoglobulins (1:2000 dilution; Daco, Glostrup, Denmark) were used as suggested by the manufacturer. Guinea pig anti-influenza NS1 [37] and rabbit anti-HIV-1 Rev [47] immunoglobulins were used in confocal laser microscopy. Also mouse monoclonal anti-nucleolin (antiC23; sc-8031; 1:100 dilution; Santa Cruz Biotechnology), mouse monoclonal anti-B23 (sc-32256; 1:200 dilution;
Santa Cruz Biotechnology) and rabbit polyclonal antifibrillarin (\#2639; 1:25 dilution; Cell Signaling Technology, Inc.) immunoglobulins were used. Secondary antibodies used were Rhodamine- Red-X- or FITC-labeled goat anti-guinea pig, anti-mouse or anti-rabbit immunoglobulins, respectively (1:100 dilution; Jackson ImmunoResearch Laboratories, Inc., West Grove, PA, USA).

\section{Plasmids and DNA manipulations}

Wild type A/Udorn/72 (H3N2 virus) NS1 gene (GenBank ID: V01102) was expressed in E. coli GST (pGEX3X; Amersham Biosciences, Buckinghamshire, U. K.) and eukaryotic pcDNA3.1(+) (Invitrogen Corp., Carlsbad, CA, USA) expression vectors. Wild type A/WSN/33 (H1N1 virus) NS1 gene (GenBank ID: M12597) was modified by PCR to create N- and C-terminal BglII sites for further cloning into the BamHI site of the pcDNA3.1(+) expression vector (Invitrogen). To create point mutations to the A/Udorn/72 and A/WSN/33 NS1 cDNAs, a QuikChange $^{\mathrm{TM}}$ Site-Directed Mutagenesis Kit (Stratagene, La Jolla, CA, USA) was used.

Wild type human nucleolin (C23; GenBank ID: BC002343), B23 (nucleophosmin; GenBank ID: BC050628), fibrillarin (FBL; GenBank ID: NM_001436.3) and HIV-1 Rev [48] genes were modified by PCR to create $\mathrm{N}$ - and C-terminal BamHI sites for further cloning into the BamHI site of the pcDNA3.1(+) expression vector (Invitrogen). Wild type human laminA/C (GenBank ID: NG_008692) gene was cloned into the pOTB7 vector (Invitrogen).

To create green fluorescence protein (GFP)-NS1 fusion constructs, N-terminal cDNAs for the wild type A/ Udorn/72 (aa 1-73) and A/WSN/33 (aa 1-73) NS1 and C-terminal cDNAs (aa 157-237 and 157-230), respectively, and C-terminal cDNA for wild type A/Brevig Mission/1/18 (aa 203-230) genes were modified by PCR to create N- and C-terminal SalI and NheI sites, respectively, for further cloning into the SalI and NheI cloning sites of a pCMX-SAH/Y145F expression vector [49]. Mutations to the GFP-NS1 chimeric gene constructs were done using the QuikChange ${ }^{\mathrm{TM}}$ Site-Directed Mutagenesis Kit (Stratagene). All oligonucleotides used to modify the genes in the study will be provided upon request.

All DNA manipulations were performed according to standard protocols, and the newly created gene constructs were partially or fully sequenced.

\section{NS1 binding assay, SDS-PAGE and Western blotting}

Influenza A virus GST-NS1 fusion proteins were expressed in E. coli BL21 cells, and GST-fusion proteins were purified as described [37]. In vitro-translated nucleolin, B23 and fibrillarin wt proteins (TNT Coupled Reticulocyte Lysate Systems, Promega, Madison, WI, USA) were $\left[{ }^{35} \mathrm{~S}\right]$-labeled (PRO-MIX, Amersham 
Biosciences) and allowed to bind to Sepharoseimmobilized GST or GST-NS1 fusion proteins on ice for $60 \mathrm{~min}$ followed by washing. GST-NS1 fusion proteinbound $\left[{ }^{35} \mathrm{~S}\right]$-labeled proteins were separated on $12 \%$ SDS-PAGE. The gels were fixed and treated with Amplify reagent (Amersham Biosciences) as specified by the manufacturer and autoradiographed. GST pull-down experiments from A549 cell extracts were carried out as described [50].

\section{Transfections, indirect immunofluorescence and confocal laser microscopy}

For indirect immunofluorescence and confocal laser microscopy $\mathrm{HuH} 7$ cells, grown on glass coverslips for $24 \mathrm{~h}$, were transfected with GFP, GFP-NS1 or HIV-1pcDNA3.1(+) expression constructs using FuGENE6 transfection reagent (Roche Diagnostics, Indiapolis, IN, USA) according to the manufacturer's instructions. Forty-eight hours after transfection the cells were fixed with 3\% paraformaldehyde at RT for $20 \mathrm{~min}$ and processed for immunofluorescence microscopy. A549 cells were infected with influenza A/Udorn/72 wt virus for 5 to 8 hours as indicated in the legends for figures, fixed with 3\% paraformaldehyde at RT for 20 min, permeabilized with $0.1 \%$ Triton X-100 for 5 min and processed for immunofluorescence microscopy. The cells, positive for transiently transfected GFP and GFP-NS1 or viral NS1 proteins, were visualized and photographed on a Leica TCS NT confocal microscope.

\section{Competing interest}

The authors declare that they have no competing interests.

\section{Authors' contributions}

KM participated in the design of the study, performed most of the experiments, analyzed the results and drafted the manuscript. JT and RF participated in the design of the study and carried out some experiments. $\mathrm{PR}$ and $\mathrm{DH}-\mathrm{V}$ provided crucial reagents to carry out the experiments and analyzed the confocal microscopy results. IJ initiated the study, participated in the design and coordination and helped to draft the manuscript. All authors have read and approved the final version of the manuscript.

\section{Acknowledgments}

We thank Johanna Rintamäki and Tuula Sirén-Vainikka for providing us with the cells, Anja Villberg and Riitta Santanen for growing up different influenza viruses and Mari Aaltonen, Sari Maljanen and Hanna Valtonen for their excellent technical assistance. We also wish to thank Dr. Adolfo Garcia-Sastre for providing us with the A/Brevig Mission/18 NS gene. This study was supported by the Medical Research Council of the Academy of Finland (grants no 252252 and 256159) and the Sigrid Juselius Foundation.

\section{Author details}

'Virology Unit, Department of Infectious Disease Surveillance and Control, National Institute for Health and Welfare (THL), Mannerheimintie 166, FIN-00300 Helsinki, Finland. ${ }^{2}$ Signaling Systems Laboratory, Department of Chemistry and Biochemistry, University of California, San Diego, La Jolla, CA 92093, USA. ${ }^{3}$ Functional Organization of the Nucleolus, RNA Biology-FRE 3402 CNRS, Université Pierre et Marie Curie, 75252 Paris cedex 5, France. ${ }^{4}$ Nuclei and Cell Cycle, Institut Jacques Monod-UMR 7592 CNRS, Université Paris Diderot, 75205 Paris cedex 13, France.
Received: 16 May 2012 Accepted: 8 August 2012

Published: 21 August 2012

\section{References}

1. Jagger BW, Wise HM, Kash JC, Walters KA, Wills NM, Xiao YL, Dunfee RL, Schwartzman LM, Ozinsky A, Bell GL, et al: An Overlapping Protein-Coding Region in Influenza A Virus Segment 3 Modulates the Host Response. Science 2012, 337:119-204.

2. Kawaoka Y, Gorman OT, Ito T, Wells K, Donis RO, Castrucci MR, Donatelli I, Webster RG: Influence of host species on the evolution of the nonstructural (NS) gene of influenza A viruses. Virus Res 1998, 55:143-156.

3. Garten RJ, Davis CT, Russell CA, Shu B, Lindstrom S, Balish A, Sessions WM, Xu X, Skepner E, Deyde V, et al: Antigenic and genetic characteristics of swine-origin $2009 \mathrm{~A}(\mathrm{H} 1 \mathrm{~N} 1)$ influenza viruses circulating in humans. Science 2009, 325:197-201.

4. Min JY, Krug RM: The primary function of RNA binding by the influenza $A$ virus NS1 protein in infected cells: Inhibiting the 2'-5' oligo (A) synthetase/RNase L pathway. Proc Natl Acad Sci U S A 2006, 103:7100-7105.

5. Mibayashi M, Martinez-Sobrido L, Loo YM, Cardenas WB, Gale M Jr, Garcia-Sastre A: Inhibition of retinoic acid-inducible gene I-mediated induction of beta interferon by the NS1 protein of influenza A virus. $J$ Virol 2007, 81:514-524.

6. Pichlmair A, Schulz O, Tan CP, Naslund TI, Liljestrom P, Weber F, Reis e Sousa C: RIG-I-mediated antiviral responses to single-stranded RNA bearing 5'-phosphates. Science 2006, 314:997-1001.

7. Kato H, Takeuchi O, Sato S, Yoneyama M, Yamamoto M, Matsui K, Uematsu S, Jung A, Kawai T, Ishii KJ, et al: Differential roles of MDA5 and RIG-I helicases in the recognition of RNA viruses. Nature 2006, 441:101-105.

8. Matikainen S, Siren J, Tissari J, Veckman V, Pirhonen J, Severa M, Sun Q, Lin R, Meri $S$, Uze $G$, et al: Tumor necrosis factor alpha enhances influenza A virus-induced expression of antiviral cytokines by activating RIG-I gene expression. J Virol 2006, 80:3515-3522.

9. Siren J, Imaizumi T, Sarkar D, Pietila T, Noah DL, Lin R, Hiscott J, Krug RM, Fisher PB, Julkunen I, Matikainen S: Retinoic acid inducible gene-I and mda- 5 are involved in influenza A virus-induced expression of antiviral cytokines. Microbes Infect 2006, 8:2013-2020.

10. Chen Z, Li Y, Krug RM: Influenza A virus NS1 protein targets poly(A)binding protein II of the cellular 3 '-end processing machinery. EMBO 1999, 18:2273-2283.

11. Li Y, Chen ZY, Wang W, Baker CC, Krug RM: The 3'-end-processing factor CPSF is required for the splicing of single-intron pre-mRNAs in vivo. RNA 2001, 7:920-931.

12. Nemeroff ME, Barabino SM, Li Y, Keller W, Krug RM: Influenza virus NS1 protein interacts with the cellular $30 \mathrm{kDa}$ subunit of CPSF and inhibits 3'end formation of cellular pre-mRNAs. Mol Cell 1998, 1:991-1000.

13. Noah DL, Twu KY, Krug RM: Cellular antiviral responses against influenza A virus are countered at the posttranscriptional level by the viral NS1A protein via its binding to a cellular protein required for the $3^{\prime}$ end processing of cellular pre-mRNAS. Virology 2003, 307:386-395.

14. Shimizu K, Iguchi A, Gomyou R, Ono Y: Influenza virus inhibits cleavage of the HSP70 pre-mRNAs at the polyadenylation site. Virology 1999, 254:213-219.

15. Twu KY, Noah DL, Rao P, Kuo RL, Krug RM: The CPSF30 binding site on the NS1A protein of influenza A virus is a potential antiviral target. J Virol 2006, 80:3957-3965.

16. Min JY, Li S, Sen GC, Krug RM: A site on the influenza A virus NS1 protein mediates both inhibition of PKR activation and temporal regulation of viral RNA synthesis. Virology 2007, 363:236-243.

17. Heikkinen LS, Kazlauskas A, Melen K, Wagner R, Ziegler T, Julkunen I, Saksela K: Avian and 1918 Spanish influenza a virus NS1 proteins bind to Crk/ CrkL Src homology 3 domains to activate host cell signaling. J Biol Chem 2008, 283:5719-5727.

18. Gack MU, Albrecht RA, Urano T, Inn KS, Huang IC, Carnero E, Farzan M Inoue S, Jung JU, Garcia-Sastre A: Influenza A virus NS1 targets the ubiquitin ligase TRIM25 to evade recognition by the host viral RNA sensor RIG-I. Cell Host Microbe 2009, 5:439-449.

19. Li S, Min JY, Krug RM, Sen GC: Binding of the influenza A virus NS1 protein to PKR mediates the inhibition of its activation by either PACT or double-stranded RNA. Virology 2006, 349:13-21. 
20. Bornholdt ZA, Prasad BV: X-ray structure of NS1 from a highly pathogenic H5N1 influenza virus. Nature 2008, 456:985-988.

21. Hale BG, Batty IH, Downes CP, Randall RE: Binding of influenza A virus NS1 protein to the inter-SH2 domain of $\mathrm{p} 85$ suggests a novel mechanism for phosphoinositide 3-kinase activation. J Biol Chem 2008, 283:1372-1380.

22. Boisvert FM, van Koningsbruggen S, Navascues J, Lamond Al: The multifunctional nucleolus. Nat Rev Mol Cell Biol 2007, 8:574-585.

23. Hernandez-Verdun D, Roussel P, Thiry M, Sirri V, Lafontaine DL: The nucleolus: structure/function relationship in RNA metabolism. Wiley Interdiscip Rev RNA 2010, 1:415-431.

24. Olson MO: Sensing cellular stress: another new function for the nucleolus? SCi STKE 2004, 2004:pe10.

25. Olson MO, Hingorani K, Szebeni A: Conventional and nonconventional roles of the nucleolus. Int Rev Cytol 2002, 219:199-266.

26. Pederson T, Tsai RY: In search of nonribosomal nucleolar protein function and regulation. J Cell Biol 2009, 184:771-776.

27. Carmo-Fonseca M: The contribution of nuclear compartmentalization to gene regulation. Cell 2002, 108:513-521.

28. Emmott $E$, Hiscox JA: Nucleolar targeting: the hub of the matter. EMBO Rep 2009, 10:231-238.

29. Hiscox JA: RNA viruses: hijacking the dynamic nucleolus. Nat Rev Microbio/ 2007, 5:119-127.

30. Olson MO, Dundr M: The moving parts of the nucleolus. Histochem Cell Biol 2005, 123:203-216.

31. Quaye IK, Toku S, Tanaka T: Sequence requirement for nucleolar localization of rat ribosomal protein L31. Eur J Cell Biol 1996, 69:151-155.

32. Macken $C$, Lu H, Goodman J, Boykin L: The value of a database in surveillance and vaccine selection. In Options for the Control of Influenza IV. Edited by Osterhaus ADME, Cox N, Hampson AW. Amsterdam: Elsevier Science; 2001:103-106.

33. Timmers AC, Stuger R, Schaap PJ, van 't Riet J, Raue HA: Nuclear and nucleolar localization of Saccharomyces cerevisiae ribosomal proteins S22 and S25. FEBS Lett 1999, 452:335-340.

34. Birbach A, Bailey ST, Ghosh S, Schmid JA: Cytosolic, nuclear and nucleolar localization signals determine subcellular distribution and activity of the NF-kappaB inducing kinase NIK. J Cell Sci 2004, 117:3615-3624.

35. Lechertier T, Sirri V, Hernandez-Verdun D, Roussel P: A B23-interacting sequence as a tool to visualize protein interactions in a cellular context. J Cell Sci 2007, 120:265-275.

36. Sirri V, Urcuqui-Inchima S, Roussel P, Hernandez-Verdun D: Nucleolus: the fascinating nuclear body. Histochem Cell Biol 2008, 129:13-31.

37. Melen K, Kinnunen L, Fagerlund R, Ikonen N, Twu KY, Krug RM, Julkunen I: Nuclear and nucleolar targeting of influenza A virus NS1 protein: striking differences between different virus subtypes. J Virol 2007, 81:5995-6006.

38. Murayama R, Harada Y, Shibata T, Kuroda K, Hayakawa S, Shimizu K, Tanaka T: Influenza A virus non-structural protein 1 (NS1) interacts with cellular multifunctional protein nucleolin during infection. Biochem Biophys Res Commun 2007, 362:880-885.

39. Li Y, Yamakita Y, Krug RM: Regulation of a nuclear export signal by an adjacent inhibitory sequence: the effector domain of the influenza virus NS1 protein. Proc Natl Acad Sci U S A 1998, 95:4864-4869.

40. Cochrane AW, Perkins A, Rosen CA: Identification of sequences important in the nucleolar localization of human immunodeficiency virus Rev: relevance of nucleolar localization to function. J Virol 1990, 64:881-885.

41. Fankhauser C, Izaurralde E, Adachi Y, Wingfield P, Laemmli UK: Specific complex of human immunodeficiency virus type $1 \mathrm{rev}$ and nucleolar B23 proteins: dissociation by the Rev response element. Mol Cell Biol 1991, 11:2567-2575.

42. Perkins A, Cochrane AW, Ruben SM, Rosen CA: Structural and functional characterization of the human immunodeficiency virus rev protein. J Acquir Immune Defic Syndr 1989, 2:256-263.

43. Qin XF, An DS, Chen IS, Baltimore D: Inhibiting HIV-1 infection in human T cells by lentiviral-mediated delivery of small interfering RNA against CCR5. Proc Natl Acad Sci U S A 2003, 100:183-188.

44. Nakabayashi H, Taketa K, Miyano K, Yamane T, Sato J: Growth of human hepatoma cells lines with differentiated functions in chemically defined medium. Cancer Res 1982, 42:3858-3863.

45. Neumann G, Watanabe T, Ito H, Watanabe S, Goto H, Gao P, Hughes M, Perez DR, Donis R, Hoffmann E, et al: Generation of influenza A viruses entirely from cloned cDNAs. Proc Natl Acad Sci U S A 1999, 96:9345-9350.
46. Gaush CR, Smith TF: Replication and plaque assay of influenza virus in an established line of canine kidney cells. Appl Microbiol 1968, 16:588-594.

47. Malim MH, Cullen BR: HIV-1 structural gene expression requires the binding of multiple Rev monomers to the viral RRE: implications for HIV-1 latency. Cell 1991, 65:241-248.

48. Malim MH, Hauber J, Fenrick R, Cullen BR: Immunodeficiency virus rev trans-activator modulates the expression of the viral regulatory genes. Nature 1988, 335:181-183.

49. Ogawa H, Inouye S, Tsuji Fl, Yasuda K, Umesono K: Localization, trafficking, and temperature-dependence of the Aequorea green fluorescent protein in cultured vertebrate cells. Proc Natl Acad Sci U S A 1995, 92:11899-11903.

50. Fagerlund R, Kinnunen L, Kohler M, Julkunen I, Melen K: NF-\{kappa\}B is transported into the nucleus by importin \{alpha\} 3 and importin \{alpha\}4. J Biol Chem 2005, 280:15942-15951.

doi:10.1186/1743-422X-9-167

Cite this article as: Melén et al:: Influenza A H3N2 subtype virus NS1 protein targets into the nucleus and binds primarily via its C-terminal NLS2/NoLS to nucleolin and fibrillarin. Virology Journal 2012 9:167.

\section{Submit your next manuscript to BioMed Central and take full advantage of:}

- Convenient online submission

- Thorough peer review

- No space constraints or color figure charges

- Immediate publication on acceptance

- Inclusion in PubMed, CAS, Scopus and Google Scholar

- Research which is freely available for redistribution 